\title{
Imaging Results Following Oncoplastic and Standard Breast Conserving Surgery
}

\author{
Ross Dolan ${ }^{a}$ Meera Patel $^{a}$ Eva Weiler-Mithoff ${ }^{b}$ James Mansella Sheila Stallard ${ }^{c}$ \\ Julie C. Doughty ${ }^{c}$ Laszlo Romics Jr. ${ }^{\text {a }}$

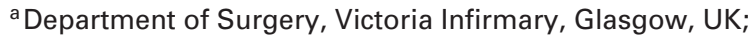 \\ ${ }^{b}$ Department of Plastic Surgery, Glasgow Royal Infirmary, Glasgow, UK; \\ ${ }^{\mathrm{c}}$ Department of Surgery, Western Infirmary Glasgow, UK
}

\section{Keywords}

Mammogram - Breast ultrasound - Biopsy · Oncoplastic . Breast conserving

\section{Summary}

Background: Oncoplastic breast-conserving surgery (OBCS) requires more complex surgical techniques than standard wide local excision (WLE) and the postoperative complication rate may be higher. Since these can have an impact on postoperative imaging, we compared imaging and biopsy results after OBCS and WLE. Methods: Findings for patients undergoing OBCS $(n=83)$ or standard WLE ( $n=128$ ) were compared. Numbers, indications and outcomes of mammograms, breast ultrasounds, magnetic resonance imaging scans and biopsies done within 2 years after surgery were analysed. Results: OBCS was applied for more advanced malignancy. Significantly more patients required breast ultrasound after OBCS than WLE (20/71 vs. 17/116; $p=0.024)$. Breast Imaging Reporting and Data System (BI-RADS) category 3 or 4 ultrasound results were found only in patients with OBCS (6/29 vs. $0 / 19 ; p=0.034)$. Significantly more biopsies were required after OBCS (9/71 vs. 3/116; $p=0.006)$. New lumps or lumpiness were the commonest indications, and pathology confirmed fat necrosis in the majority (7/12). The rate of fat necrosis after OBCS was $18 \%$ on clinical examination (13/71), 15\% with ultrasound (11/71) and $7 \%$ confirmed on pathology (5/71). Conclusion: Patients treated with OBCS require significantly more ultrasound scans and consequent biopsies than patients who underwent WLE. This is mainly due to fat necrosis developing after OBCS in the majority of cases.

(c) 2015 S. Karger GmbH, Freiburg

\section{Introduction}

Oncological safety and aesthetic outcome have become common goals in breast cancer surgical treatment [1]. Breast conservation surgery is offered to women with relatively large or poorly located cancers and involves specialized plastic surgical techniques in combination with oncological surgery, commonly referred as oncoplastic breast-conserving surgery (OBCS) [2].

Indications and outcomes of breast imaging after OBCS are influenced by the surgical technique as well as the postoperative complication rate [3,4]. Extensive parenchymal manipulation, older age, high body mass index (BMI), large tumour size and medical risk factors that are irreversible over a short term increase the complication rate to $27 \%$ in OBCS patients [3,5-9].

So far, only 3 studies have reported on imaging findings after OBCS $[4,10,11] ; 2$ describing results after volume-replacement OBCS only $[10,11]$ and 1 showing results after oncoplastic conservation with breast reduction techniques in comparison to standard wide excision [4]. Arguably, OBCS may not be directly comparable to standard surgical techniques. However, numerous studies have already been published to benchmark emerging evidence of this relatively new technique compared to well-established standard breast surgery $[2,12]$. We, therefore, performed a retrospective analysis of postoperative imaging and biopsies, comparing the numbers, indications and outcomes of mammograms, breast ultrasound and magnetic resonance imaging (MRI) scans, and breast biopsies taken in the first 2 years after OBCS and wide local excision (WLE).

\section{Methods}

Consecutive patients treated with OBCS in 2 breast units (Victoria Infirmary and Western Infirmary in Glasgow) between May 2009 and December 2011 were enrolled in the analysis. Patients treated with standard WLE in the Victoria Infirmary breast unit between February and December 2010 were in-

\section{KARGER \\ Fax +497614520714


cluded in the control arm. Details of patients treated with OBCS are kept in a prospectively maintained institutional standardized database in these 2 Glasgow breast units. Patients treated with simple WLE were identified from the West of Scotland Managed Clinical Networks (Breast Cancer) database.

Imaging and biopsies required during the first 24 months of the postoperative follow-up period were analysed. The number, indication and outcome of these investigations were compared in between the 2 groups. Patients from both groups received a physical examination every 12 months in the follow-up clinic. Bilateral mammograms were carried out routinely at the first follow-up. The majority of patients had a second mammogram 24 months after surgery. For a minority of the patients in the OBCS group who were treated in the Western Infirmary $(\mathrm{n}=16)$, the second postoperative surveillance mammogram was arranged for 36 months post surgery. Imaging was performed by the same group of radiologists for all patients. All radiology results were categorized according to BI-RADS (Breast Imaging Reporting and Data System) assessment categories published by the American College of Radiology [13].

The decision on indication and technique of OBCS was taken by either an oncoplastic breast surgeon alone, or a breast and a plastic surgeon together [2, 12]. Patients at risk for developing significant postoperative breast deformity with standard WLE techniques were considered for OBCS. This was primarily based on preoperative clinical and radiological evaluation of the ratio between the planned excision volume and the breast volume. The oncoplastic technique was determined by patients' anatomy, preferences and tumour location. When breast reshaping could be achieved with the remaining breast tissue, a tumourspecific breast reduction technique was applied (volume displacement technique). A pedicled flap from the vicinity was used to replace the resected tissue when the remaining breast tissue was insufficient for reshaping (volume replacement technique). Patients were not offered OBCS if they had at least 2 of the following 4 risk factors for wound-healing problems: a BMI > 34, a smoking habit, vasculitis, and immunosuppression. In terms of technical complexity, patients who underwent significant volume excision and were subsequently treated by a volume displacement technique accompanied by adequate skin envelope reduction, or a true volume replacement technique, were included in the OBCS study group (level II oncoplastic techniques as defined by Clough et al. [8]). Simple reshaping, which is routinely performed for smaller lesions to prevent deformity, was considered as WLE.

Statistical calculations were performed using SPSS ${ }^{\circledR}$ Statistics version 20.0 (SPSS, Chicago, IL, USA). For comparisons of overall number of imaging or biopsies, the mean number of imaging or biopsies per patient was used since the median value would be always 2 for mammograms and 0 for ultrasound, MRI and breast biopsies. Mean number of mammograms was adjusted to differences in mammographic follow-up between the 2 units. A 2-tailed MannWhitney test was used to calculate statistical difference for median age and mean number of imaging or biopsies. A 2-tailed Z-test was used to calculate the difference between the 2 groups in the proportion of patients undergoing ultrasound scans or biopsies. Differences were considered statistically significant when the p value was less than 0.05 .

\section{Results}

During the time period mentioned above, 211 patients were treated with either OBCS $(\mathrm{n}=83)$ or WLE $(\mathrm{n}=128) .11$ patients were excluded from the OBCS group and 10 from WLE group because they required completion mastectomy for incomplete margins after breast conservation. 1 patient from the OBCS group who had a Grisotti flap for squamous cell carcinoma on her nipple requiring no follow-up imaging was also excluded. The data for 2 further patients who died within the 2-year follow-up period (1 with breast cancer-related death) were omitted from the WLE group. Therefore, for this study, 71 patients were included in the OBCS group, and 116 in the WLE group.
Table 1. Surgical techniques and symmetrisation rate in patients treated with OBCS

\begin{tabular}{|c|c|c|c|c|c|}
\hline \multirow{2}{*}{$\begin{array}{l}\text { Classification of } \\
\text { oncoplasty }\end{array}$} & \multirow{2}{*}{$\begin{array}{l}\text { Surgical } \\
\text { technique }\end{array}$} & \multicolumn{2}{|c|}{ Patients } & \multicolumn{2}{|c|}{ Symmetrisation } \\
\hline & & $\mathrm{n}$ & $\%^{\mathrm{a}}$ & $\mathrm{n}$ & $\%^{\mathrm{b}}$ \\
\hline \multirow{5}{*}{$\begin{array}{l}\text { Volume } \\
\text { replacement }\end{array}$} & Benelli & 12 & 17 & 0 & $\mathrm{n} / \mathrm{a}$ \\
\hline & Wise pattern & 44 & 62 & 26 & 59 \\
\hline & Melon slice & 1 & 1.4 & 1 & 100 \\
\hline & Tennis racquet & 3 & 4.2 & 1 & 33 \\
\hline & Le Jour & 1 & 1.4 & 1 & 100 \\
\hline \multirow{3}{*}{$\begin{array}{l}\text { Volume } \\
\text { displacement }\end{array}$} & T-EF & 6 & 8.4 & 0 & $\mathrm{n} / \mathrm{a}$ \\
\hline & Matrix rotation & 3 & 4.2 & 0 & $\mathrm{n} / \mathrm{a}$ \\
\hline & T-DAP & 1 & 1.4 & 0 & $\mathrm{n} / \mathrm{a}$ \\
\hline
\end{tabular}

OBCS $=$ oncoplastic breast-conserving surgery, $\mathrm{n} / \mathrm{a}=$ not applicable,

$\mathrm{T}$-EF $=$ thoraco-epigastric flap, $\mathrm{T}$-DAP $=$ thoracodorsal artery perforator flap. apercentage of patients altogether.

bercentage of patients within the given oncoplastic technique.

For the initial 211 patients investigated, the incomplete margin rate was 16\% (13/83) after OBCS and 18\% (23/128) after standard WLE. Of these, in the OBCS group 2 patients had to undergo wider excision and 11 patients had completion mastectomy, and in the WLE group 13 patients had wider excision and 10 patients completion mastectomy.

Patients treated with OBCS were significantly younger (median age 54 years, range $24-79$ years) than those treated with WLE (median age 61 years, range $44-88$ years) $(\mathrm{p}=0)$. Oncoplastic surgical techniques applied for oncoplastic conservation were mainly volume displacement techniques $(n=61)$; volume replacement was used much less frequently $(n=10)$. Contralateral symmetrisation was carried out in 29 patients (table 1). 2 patients had bilateral breast cancers; of these, 1 underwent a Benelli type reduction mammoplasty on 1 side and a skin-sparing mastectomy and immediate breast reconstruction with extended autologous latissimus dorsi flap on the contralateral side, and the other bilateral reduction mammoplasties from Wise pattern incisions. In terms of postoperative complication rates, 5 patients (7\%) from the OBCS group required reoperation for complications (debridement \pm grafting in 3 patients, re-closure of wound in 1 patient and evacuation of haematoma in 1 patient). 3 (2.6\%) patients required reoperation for complications in the WLE group ( 2 needed evacuation of haematoma and 1 incision and drainage of an abscess).

Patients treated with OBCS had more advanced malignant disease compared to patients undergoing standard WLE, which was reflected by more invasive cancers, larger tumour size, higher tumour grade and more involved axillary nodes in the OBCS group (table 2). Consequently, many more patients from the OBCS group received chemotherapy compared to the WLE group (table 3 ).

The mean number of breast ultrasounds per OBCS patient was almost twice that for the WLE patients (OBCS: 0.394, range 0-6 vs. WLE: 0.211 , range $0-2 ; \mathrm{p}=0.116)$. However, the mean number of mammograms per patient (OBCS: 2 , range $0-3$ vs. WLE: 1.914, range $0-3 ; \mathrm{p}=0.327$ ) and breast MRI scans (OBCS: 0.028, range $0-2$ vs. WLE: 0.069 , range $0-2 ; \mathrm{p}=0.674$ ) were similar in the 2 
Table 2. Common histopathological characteristics of patients treated with OBCS

\begin{tabular}{|c|c|c|}
\hline Characteristics & $\begin{array}{l}\text { OBCS, n } \\
(\%)\end{array}$ & $\begin{array}{l}\text { WLE, } \mathrm{n} \\
(\%)\end{array}$ \\
\hline \multicolumn{3}{|l|}{ Histological type } \\
\hline DCIS & $3(4.2)$ & $18(15)$ \\
\hline Ductal/NST & $60(84)$ & $86(74)$ \\
\hline Lobular & $4(5.6)$ & $6(5.2)$ \\
\hline Other & $4(5.6)$ & $6(5.2)$ \\
\hline \multicolumn{3}{|l|}{ Tumour size $^{\mathrm{a}}$} \\
\hline $\mathrm{T}_{\text {is }}$ & $3(4.2)$ & $18(15)$ \\
\hline $\mathrm{T} 1$ & $31(44)$ & $93(81)$ \\
\hline $\mathrm{T} 2$ & $32(45)$ & $5(4.3)$ \\
\hline T3 & $4(5.6)$ & 0 \\
\hline \multicolumn{3}{|l|}{ Grade $^{b}$} \\
\hline 1 & $6(8.8)$ & $24(24)$ \\
\hline 2 & $25(37)$ & $54(55)$ \\
\hline 3 & $37(54)$ & $20(20)$ \\
\hline \multicolumn{3}{|l|}{ Involved nodes ${ }^{\mathrm{b}}$} \\
\hline 0 & $43(63)$ & $85(87)$ \\
\hline $1-3$ & $21(31)$ & $11(11)$ \\
\hline$>3$ & $4(5.9)$ & $2(2)$ \\
\hline \multicolumn{3}{|l|}{$\mathrm{ER}^{\mathrm{b}}$} \\
\hline Positive & $54(79)$ & $90(92)$ \\
\hline Negative & $14(21)$ & $8(8.2)$ \\
\hline \multicolumn{3}{|l|}{$\mathrm{PR}^{\mathrm{b}}$} \\
\hline Positive & $45(66)$ & $83(85)$ \\
\hline Negative & $23(34)$ & $15(15)$ \\
\hline \multicolumn{3}{|l|}{ HER- $2^{b}$} \\
\hline Positive & $10(17)$ & $10(10)$ \\
\hline Negative & $58(85)$ & $88(90)$ \\
\hline \multicolumn{3}{|c|}{$\begin{array}{l}\text { WLE = wide local excision, DCIS = ductal carci- } \\
\text { noma in situ, NST = no special type, ER = oestro- } \\
\text { gen receptor, PR = progesterone receptor, HER-2 } \\
\text { = human epidermal growth factor receptor } 2 . \\
\text { aOne patient in each group underwent neo- } \\
\text { adjuvant chemotherapy, and had complete patho- } \\
\text { logical response prior to OBCS. } \\
\text { bInvasive cancers only. }\end{array}$} \\
\hline
\end{tabular}

Table 3. Adjuvant radio-, chemo- and hormonal therapy in patients treated with OBCS or standard WLE

\begin{tabular}{lcll}
\hline & $\begin{array}{l}\text { Radiotherapy for } \\
\text { DCIS + invasive } \\
\text { ca., n (\%) }\end{array}$ & $\begin{array}{l}\text { Chemotherapy for } \\
\text { invasive ca. only } \\
\mathrm{n}(\%)\end{array}$ & $\begin{array}{l}\text { Endocrine therapy } \\
\text { for invasive ca. only, } \\
\mathrm{n}(\%)\end{array}$ \\
\hline OBCS & $70(99)$ & $38(56)$ & $51(75)$ \\
WLE & $114(98)$ & $23(23)$ & $94(96)$ \\
\hline
\end{tabular}

ca. $=$ cancer.

${ }^{\mathrm{a} O n e}$ patient in each group underwent neoadjuvant chemotherapy. groups. Finally, the total number of imaging per patient was also similar between the 2 groups (OBCS: 2.186 , range $0-8$ vs. WLE: 2.146 , range $0-5 ; \mathrm{p}=0.857$ ).

Significantly more patients in the OBCS group required breast ultrasound compared to to the WLE group (OBCS: 20/71 vs. WLE: $17 / 116$ patients; $p=0.024)$. Altogether, 29 ultrasounds were carried out in the 71 patients treated with OBCS: 15 of these patients had 1 ultrasound, 4 required 2 scans, while 1 patient had 6 breast ultrasounds. 19 breast ultrasounds were carried out in the 116 patients who underwent WLE. In this group 15 patients had 1 ultrasound scan, and 2 patients required 2 ultrasound scans. 'Indeterminate' or 'suspicious' (BI-RADS category 3 or 4) ultrasound results were detected only in the OBCS group (OBCS: 6/29 ultrasound scans; $\mathrm{p}=0.034$ ). All ultrasound scans were either 'normal' or showed only 'benign' changes after WLE (BI-RADS category 1 or 2) (table 4).

Common indications for breast ultrasound were lumps felt on clinical examination or suspicion of underlying collection in association with cellulitis and/or leakage through the wound in the OBCS group (table 5). A similar proportion of patients receiving volume displacement or volume replacement oncoplastic surgery required breast ultrasound ( $16 / 61$ vs. $4 / 10 ; \mathrm{p}=0.36$ ), although there was a trend for patients with volume replacement to require more ultrasound scans (table 5). 9 of the 20 patients who required breast ultrasound in the OBCS group underwent immediate symmetrisation surgery. Of those, 7 required ultrasound on the treated breast, while 2 patients had ultrasound on the reduced side.

Significantly more patients from the OBCS group required breast biopsy compared with the WLE group (9/71 vs. 3/116; $\mathrm{p}=0.006$ ). All of these patients underwent a core biopsy, except 1 who had a punch biopsy of the dermis. In the majority of cases, indications for biopsies were a new distinct lump or a lumpy area, and the biopsy confirmed fat necrosis in most patients (table 6). The fat necrosis rate after OBCS was $18 \%$ on clinical examination, $15 \%$ with ultrasound, and $7 \%$ of those were confirmed on pathology (tables 5 and 6). An additional biopsy from the pelvic bone was carried out in 1 patient treated with OBCS to investigate the possibility of distant metastatic disease. This biopsy was normal and was not involved in the calculation.

\section{Discussion}

This study showed that, compared to WLE, OBCS was applied to patients with more advanced malignant disease, which is consistent with our previously published results [2]. More ultrasound
Table 4. BI-RADS categories of postoperative mammograms, ultrasounds and breast MRI in patients treated with OBCS or WLE

\begin{tabular}{lllllllllllll}
\hline & $\mathrm{R} 1$ & $\mathrm{U} 1$ & $\mathrm{M} 1$ & $\mathrm{R} 2$ & $\mathrm{U} 2$ & $\mathrm{M} 2$ & $\mathrm{R} 3$ & $\mathrm{U} 3$ & $\mathrm{M} 3$ & $\mathrm{R} 4$ & $\mathrm{U} 4$ & $\mathrm{M} 4$ \\
\hline OBCS, n & 3 & 1 & 0 & 109 & 22 & 2 & 2 & 5 & 0 & 2 & 1 & 0 \\
WLE, n & 0 & 2 & 0 & 218 & 17 & 6 & 3 & 0 & 1 & 0 & 0 & 0 \\
\hline
\end{tabular}

BI-RADS = Breast Imaging Reporting and Data System, $\mathrm{R}=$ mammogram, $\mathrm{U}=$ ultrasound, $\mathrm{M}=$ breast MRI, MRI = magnetic resonance imaging.

Number of imaging is presented under various BI-RADS categories. There was no BI-RADS category 5 result in any of these imaging modalities. 
Table 5. Indications, numbers and outcomes of postoperative ultrasound scans and consequent biopsies in patients treated with various oncoplastic surgical techniques
Table 6. Indications, numbers and outcomes of postoperative biopsies in patients treated with oncoplastic or standard breast-conserving surgery

\begin{tabular}{|c|c|c|c|c|c|}
\hline $\begin{array}{l}\text { Indications } \\
\text { for US }\end{array}$ & US scans ${ }^{\mathrm{a}}$ & $\begin{array}{l}\text { Outcome of } \\
\text { US scans }{ }^{\text {b }}\end{array}$ & Biopsy $^{c}$ & $\begin{array}{l}\text { Patients, } \\
\mathrm{n}\end{array}$ & $\begin{array}{l}\text { Surgical } \\
\text { technique }^{\mathrm{d}}\end{array}$ \\
\hline Lump & 16 & $\begin{array}{l}\text { U4 (1) } \\
\text { U3 (3) } \\
\text { U2 (11) } \\
\text { U1 (1) }\end{array}$ & 4 & 11 & $\begin{array}{l}\text { Wise pattern }(8) \\
\text { Matrix rotation (1) } \\
\text { T-EF (1) } \\
\text { Le Jour (1) }\end{array}$ \\
\hline Collection & 8 & U2 (8) & 0 & 5 & $\begin{array}{l}\text { Wise pattern (4) } \\
\text { Benelli (1) }\end{array}$ \\
\hline Lumpy area & 2 & $\begin{array}{l}\text { U3 (1) } \\
\text { U2 (1) }\end{array}$ & 2 & 2 & Wise pattern (2) \\
\hline Pain & 2 & $\begin{array}{l}\text { U3 (1) } \\
\text { U2 (1) }\end{array}$ & 1 & 2 & $\begin{array}{l}\text { Benelli }(1) \\
\text { Matrix rotation (1) }\end{array}$ \\
\hline MMG calc. & 1 & U2 (1) & 0 & 1 & Thoraco-epig. (1) \\
\hline
\end{tabular}

US = ultrasound, $\mathrm{T}-\mathrm{EF}=$ thoraco-epigastric flap, $\mathrm{MMG}$ calc. $=$ mammographic microcalcification. ${ }^{a}$ Number of scans.

${ }^{b}$ Number of BI-RADS category reports in parentheses.

'Number of biopsies taken.

dNumber of cases in parentheses.

\begin{tabular}{|c|c|c|c|c|}
\hline $\begin{array}{l}\text { Indications for } \\
\text { biopsy }\end{array}$ & Patients, $\mathrm{n}$ & Outcome of biopsy ${ }^{\mathrm{a}}$ & Surgical technique ${ }^{\mathrm{b}}$ & Previous imaging ${ }^{c}$ \\
\hline Distinct lump & 7 & $\begin{array}{l}\text { fat necrosis (3) } \\
\text { edge of seroma (1) } \\
\text { fibrosis (1) } \\
\text { foreign body reaction } \\
\text { (1) } \\
\text { normal (1) }\end{array}$ & $\begin{array}{l}\text { OBCS - Wise pattern } \\
(4) \\
\text { OBCS - Benelli (1) } \\
\text { WLE (2) }\end{array}$ & $\begin{array}{l}\text { U4 (1) } \\
\text { U3 (3) } \\
\text { U2 (2) }\end{array}$ \\
\hline Lumpy area & 2 & fat necrosis (2) & $\begin{array}{l}\text { OBCS - Wise pattern } \\
\text { (1) } \\
\text { OBCS - Benelli (1) }\end{array}$ & $\mathrm{U} 2(2)$ \\
\hline MMG calc. & 1 & fat necrosis (1) & $\begin{array}{l}\text { OBCS - Wise pattern } \\
\text { (1) }\end{array}$ & $\mathrm{R} 4$ (1) \\
\hline $\begin{array}{r}\text { Indeterminate } \\
\text { US finding }\end{array}$ & 1 & fat necrosis (1) & $\begin{array}{l}\text { OBCS - Wise pattern } \\
\text { (1) }\end{array}$ & U3 (1) \\
\hline Dermatitis & 1 & dermal inflammation (1) & WLE (1) & U1 (1) \\
\hline
\end{tabular}

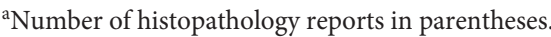

${ }^{b}$ Number of cases in parentheses.

${ }^{c}$ Number of BI-RADS category reports in parentheses. scans and biopsies were necessary after OBCS than after simple WLE. These investigations were required for benign causes, e.g. lumps, lumpiness or collections (table 5). Ultrasonographic findings were mostly benign, but indeterminate and suspicious outcomes were also noted after OBCS (table 4). Biopsy results were also benign, fat necrosis being the most common finding. No local recurrence was diagnosed, which is probably due to the relatively short follow-up time [6, 14].

Since mammograms are not adversely affected after aesthetic breast reduction, surveillance mammograms after OBCS may also not be impeded [15]. Losken et al. [4] demonstrated that 'mammographic stabilisation' is delayed after OBCS compared to WLE, but that overall mammographic findings, including architectural distortion, cysts, and calcification, are similar. Monticciolo et al. [10] showed that mammographic findings are predictive even after volume replacement with a mini-latissimus dorsi flap. Common mammographic changes visible after OBCS include parenchymal redistribution, dermal calcification along the skin incisions and repositioned nipples, and fibrous bands extending to the nipple-areola complex [15]. Mammographic microcalcification is rarely a confounding factor after OBCS, unless it is followed or accompanied by autologous fat grafting. In those cases, microcalcification can occur in $13 \%$ of patients, while oil cyst formation (a special form of fat necrosis) develops in up to $90 \%$ of patients [16]. In our study, the mean number of mammograms per patients was almost identical in the 2 groups. Microcalcification was found in 2 patients who had OBCS, but none after WLE; 1 of the 2 cases required biopsy, which showed fat necrosis. 
Reduction mammoplasty, however, increases the development of fat necrosis and the incidence of masses requiring further imaging and ultimately biopsy [17]. This may indicate that OBCS (volume displacement technique in particular) may contribute to the development of breast lumps or lumpy areas that need to be further investigated. In comparative studies of OBCS and WLE, an increased trend towards ultrasound was found after OBCS $[4,18]$. Indeed, a significantly higher proportion of patients in our study also required ultrasound after OBCS. Breast lumps or lumpiness were the indications for ultrasound scans in $62 \%$ of patients treated with OBCS (13/21) (table 5). Finally, lumps or lumpy area were the indication for truecut biopsy in all but 1 patient (6/7) in the OBCS group (table 5).

Fat necrosis, as complication of OBCS, has been reported to be found in $6.3-26 \%$ of patients $[3,5-7,19,20]$. It has been suggested that the rate of fat necrosis is higher after OBCS than after reduction mammoplasty or lumpectomy $[5,6]$. However, the authors did not report whether the fat necrosis was detected by clinical, radiological or pathological diagnosis in their series. In our study, the rate of fat necrosis was $7-18 \%$, depending on the method for diagnosis (tables 5 and 6). Clough et al. [8] suggested that the fat necrosis rate can be reduced by the integration of glandular density in the careful planning of the oncoplastic technique. Low-density breast tissue with a major fatty composition carries a higher risk of fat necrosis after extensive undermining; hence, widespread dual plane mobilization should be avoided in these cases [8].

The limitation of our study is that it reflects the practice of relatively few surgeons and radiologists in 2 breast units. In fact, all patients who were treated with standard WLE were from 1 unit, in which the majority of OBCS patients were also treated. In addition, this study reflects a relatively early phase in the learning curve for OBCS techniques, which have since become part of routine prac- tice. Therefore, it is conceivable that in other units in which the indications and applications of various OBCS practices were developed earlier, these differences in postoperative breast ultrasounds and biopsies may have diminished earlier.

Indications for further investigation of postoperative lumpiness or distinct lumps in the operated breast may be subjective. While most surgeons would request at least a breast ultrasound scan, a fine needle aspiration or a true-cut biopsy may also be appropriate even if the clinical examination and imaging correlate fully. The anxiety level for surgeons and radiologists are understandably higher at the initial phase of the learning curve of a new surgical technique. In addition, patients with a recent diagnosis of breast cancer may, understandably, be very concerned about lumps in their treated breast. It is conceivable that increasing experience and familiarity with postoperative findings after OBCS will decrease this anxiety, so that postoperative investigations will be less frequent in the future.

In conclusion, patients treated with OBCS required significantly more ultrasound scans and consequent biopsies. New lumps or lumpiness were the commonest indications, and pathology confirmed fat necrosis in the majority of cases.

\section{Acknowledgement}

Special thanks to Gillian Bentley, Cancer Audit Facilitator for providing patients' data (West of Scotland Managed Clinical Network, Glasgow, UK).

\section{Disclosure Statement}

None of the authors declared conflict of interest. No ethical approval was required for this study.

\section{References}

1 Romics L Jr, Chew BK, Weiler-Mithoff E, et al.: Tenyear follow-up of skin-sparing mastectomy followed by immediate breast reconstruction. Br J Surg 2012;99: 799-806.

2 Mansell J, Weiler-Mithoff E, Martin J, et al.: How to compare the oncological safety of oncoplastic breast conservation surgery - to wide local excision or mastectomy? Breast 2015;24:497-501.

3 Hamdi M: Oncoplastic and reconstructive surgery of the breast. Breast 2013;22 Suppl 2:S100-105.

4 Losken A, Schaefer TG, Newell M, Styblo TM: The impact of partial breast reconstruction using reduction techniques on postoperative cancer surveillance. Plast Reconstr Surg 2009;124:9-17.

5 Tenofsky PL, Dowell P, Topalovski T, Helmer SD: Surgical, oncologic, and cosmetic differences between oncoplastic and nononcoplastic breast conserving surgery in breast cancer patients. Am J Surg 2014;207: 398-402; discussion 402.

6 McCulley SJ, Macmillan RD: Therapeutic mammaplasty-analysis of 50 consecutive cases. Br J Plast Surg 2005;58:902-907.

7 Spear SL, Pelletiere CV, Wolfe AJ, et al.: Experience with reduction mammaplasty combined with breast conservation therapy in the treatment of breast cancer. Plast Reconstr Surg 2003;111:1102-1109.
8 Clough KB, Kaufman GJ, Nos C, et al.: Improving breast cancer surgery: A classification and quadrant per quadrant atlas for oncoplastic surgery. Ann Surg Oncol 2010;17:1375-1391.

9 Macmillan RD, James R, Gale KL, McCulley SJ: Therapeutic mammaplasty. J Surg Oncol 2014;110:90-95.

10 Monticciolo DL, Ross D, Bostwick J 3rd, et al.: Autologous breast reconstruction with endoscopic latissimus dorsi musculosubcutaneous flaps in patients choosing breast-conserving therapy: Mammographic appearance. AJR Am J Roentgenol 1996;167:385-389.

11 Tan VK, Cornford EJ, McCulley SJ, Macmillan RD: Qualitative mammographic findings and outcomes of surveillance mammography after partial breast reconstruction with an autologous flap. J Surg Oncol 2015; 111:377-381.

12 Khan J, Barrett S, Forte C, et al.: Oncoplastic breast conservation does not lead to a delay in the commencement of adjuvant chemotherapy in breast cancer patients. Eur J Surg Oncol 2013;39:887-891.

13 D'Orsi CJ, Sickles EA, Mendelson EB, Morris EA: ACR BI-RADS Atlas, Breast Imaging and Reporting Data System. Reston, VA, 2013.

14 Rietjens M, Urban CA, Rey PC, et al.: Long-term oncological results of breast conservative treatment with oncoplastic surgery. Breast 2007;16:387-395.
15 Margolis NE, Morley C, Lotfi P, et al.: Update on imaging of the postsurgical breast. Radiographics 2014;34: 642-660.

16 Berg WA, Sechtin AG, Marques H, Zhang Z: Cystic breast masses and the ACRIN 6666 experience. Radiol Clin North Am 2010;48:931-987.

17 Rubin JP, Coon D, Zuley M, et al.: Mammographic changes after fat transfer to the breast compared with changes after breast reduction: A blinded study. Plast Reconstr Surg 2012;129:1029-1038.

18 Gale K, Cornford E, Macmillan RD: Imaging post therapeutic mammaplasty. Eur J Surg Oncol 2014;40:603.

19 Chang E, Johnson N, Webber B, et al.: Bilateral reduction mammoplasty in combination with lumpectomy for treatment of breast cancer in patients with macromastia. Am J Surg 2004; 187:647-650; discussion 650641.

20 Imahiyerobo TA, Pharmer LA, Swistel AJ, Talmor M: A comparative retrospective analysis of complications after oncoplastic breast reduction and breast reduction for benign macromastia: Are these procedures equally safe? Ann Plast Surg 2014;[Epub ahead of print]. 